\title{
PRIMER CONGRESO INTERNACIONAL DE INVESTIGADORES EN BIOÉTICA GLOBAL, DERECHOS HUMANOS, EDUCACIÓN Y SALUD

\author{
FACULTAD DE MEDICINA, BENEMÉRITA UNIVERSIDAD \\ AUTÓNOMA DE PUEBLA-FMBUAP/2018
}

El objetivo del Congreso fue dialogar los compromisos y retos de las universidades con las comunidades en cumplimiento de los paradigmas bioéticos, en derechos humanos y la educación, como quehacer multidisciplinario para alcanzar una salud global para las generaciones actuales y futuras en convivencia con el universo.

Este "Primer Congreso Internacional de Investigadores en Bioética Global, Derechos Humanos, Educación y Salud" (agosto 2018, Puebla, México) tuvo como fundamento dialogar las propuestas del Comité Internacional de Bioética de la UNESCO, para generar premisas que no solo difundan, sino también generen compromisos claros de las universidades privadas y públicas, como la Benemérita Universidad Autónoma de Puebla (BUAP), la Universidad Nacional Autónoma de México (UNAM), el Instituto Politécnico Nacional (IPN), así como las instituciones de los servicios de salud en México y otras universidades de América Latina participantes de este escenario internacional, como es la Universidad de Chile, con la presencia del Dr. Fernando Lolas Stepke, profesor e investigador.

En este escenario académico y de investigación, se brindó un homenaje al Dr. Manuel Velasco Suárez (Chiapas, México 1914-2001), por su "legado en bioética". El Dr. Fernando Lolas Stepke se refirió “... al científico como iniciador de la Bioética en México, un hombre de ciencias y de letras, autor de libros y de trabajos científicos publicados en revistas especializadas nacionales e internacionales; quien dictó centenares de conferencias en México y el mundo; asimismo, recibió múltiples condecoraciones y distinciones de universidades, de organismos públicos y privados; además de haber sido galardonado con varios títulos honorarios otorgados por gobiernos de diferentes países de los diversos continentes del mundo". El Dr. Manuel Velasco-Suárez (2002+), fundó la Comisión Nacional de Bioética (CNMB, 1992). Fue el primer Presidente de la Academia Nacional Mexicana de Bioética (1995). Así, es reconocido y reconocible el legado del Dr. Manuel Velasco-Suárez, quien afirmaba: "La bioética... No es la 'ética' de la vida, sino el estudio y la reflexión sistemáticos de la conducta hacia la vida, la salud y los derechos humanos, a la luz de los avances de las ciencias biológicas y las necesarias reflexiones filosóficas de la "ética" (Dr. Fernando Lolas Stepke, BUAP 2018). En el tenor de una interesante mesa de diálogo, el Dr. José Luis Gándara Ramírez (Director de la FMBUAP, 2018) presentó el libro Ética del Desarrollo Sostenible de la Cátedra ANUIES-UNACH “Dr. Manuel Velasco-Suárez”. El Mtro. Carlos Eugenio Ruiz Hernández, rector de la Universidad Nacional Autónoma de Chiapas (UNACH), manifestó que la Cátedra ANUIES-UNACH "Manuel Velasco-Suárez: Bioética para la Salud y la Educación", es un reconocimiento a la enorme aportación científica del neurocirujano, Premio Nobel de la Paz 1985, promotor de la Bioética. El Dr. Jesús Agustín Velasco-Suárez Siles, quien recibió el reconocimiento universitario (BUAP, 2018) in memoriam al Legado en Bioética, Educación y Salud, agradeció este homenaje y explicó que la Cátedra ANUIES-UNACH busca cumplir con los objetivos de la Agenda Mundial 2030, con una nueva Cátedra "Dr. Manuel Velasco Suárez: Ética del Desarrollo Sostenible". Finalmente se invitó al Dr. José Luis Gándara Ramírez a crear un proyecto conjunto FMBUAP-Cátedra ANUIES-UNACH.

Las líneas de investigación abordadas en este "Primer Congreso de Investigadores en Bioética Global, Derechos Humanos, Educación y Salud" (BUAP, 2018) fueron tres: "Bioética global derechos huma- 
nos, grupos vulnerables y perspectiva de género"; "Experiencias Universitarias en Bioética, Derechos Humanos y Cambio Climático, y "Acto Profesional y Comisiones de Bioética en México".

Se generan compromisos académicos y de investigación asociados con las universidades e instituciones clínicas participantes, para consolidar proyectos de vinculación interinstitucionales, interdisciplinarios y pluriculturales, con los trabajos aquí presentados. De tal manera que se motive a las comunidades de profesionales a ejercer una práctica más legítima y veraz en relación con "la bioética global, los derechos humanos con perspectiva de género, la educación crítica y veraz para alcanzar una salud global, es decir, incluyente de la especie humana con la biodiversidad universal". En este contexto, se destacan la razón y la conciencia, para que actuemos de la mejor manera. Así, el verdadero compromiso educativo es a través del diálogo, de la solidaridad profesional, con decisiones e iniciativas en beneficio de situaciones concretas" (Lolas F. Ética e Innovación Tecnológica. Santiago de Chile: CIEB, Universidad de Chile; 2006: 56).

Mariana Paula Loyola Gutiérrez, María Teresa Abad Camacho

Facultad de Medicina, Benemérita Universidad Autónoma de Puebla-FMBUAP 